\title{
Introduction to a roundtable on the governance of open source software: particular solutions and general lessons
}

\author{
Paul B. de Laat
}

Published online: 9 June 2007

(C) Springer Science+Business Media B.V. 2007

In the spring of 2006, the editors of the JMG asked me to stage a roundtable discussion about the topic of governance of open source software (OSS). In a call for papers the theme was announced as follows. "Since the year 2000, the phenomenon of OSS is increasingly attracting scholarly attention. How do hackers succeed in governing a seemingly chaotic process of hundreds (if not thousands) of volunteers working together? How is this apparent self-governance to be explained? Throughout, it would seem to be important to differentiate the concept of governance into governance in a strict sense: steering the actual cooperation of volunteers, and governance in a broad sense: creating wider institutional conditions for the movement to flourish as a whole. The central question of this JMGdiscussion then becomes: what instruments are at play in open source governancein both a strict and a broad sense?",

Thereupon, the following set of questions was posed to the participants in order to open up discussion:

- Is the process of OSS production governed mainly by means of incentives, control, or trust? Or, more accurately, assuming that differences obtain between various OSS groups, what is the 'bandwidth' of incentives/control/trust actually in use for governing 'production' processes? And to what extent this balance has changed over time?

- If in your opinion incentives play a role in self-governance of open source groups, can you explain how such governance looks like (e.g., reputation concerns)?

\footnotetext{
P. B. de Laat $(\bowtie)$

Faculty of Philosophy, University of Groningen, Oude Boteringestraat 52, 9712 GL Groningen,

The Netherlands

e-mail: P.B.de.Laat@rug.nl
} 
- If in your opinion control applies to open source groups, what do you consider to be its main instruments as related to governance (e.g., hierarchical division of tasks, grading of file access, licensing)?

- If according to you trust applies to open source groups, what do you consider to be its main governance mechanisms (e.g., arrangements for committing code, procedures for code acceptance)?

- Concerning trust in particular: if participants turn out to trust each other, do you consider participants to infer trust (if so: from what sources) or simply to assume trust (cf. theories about 'swift trust')?

Subsequently, attention was drawn to multiple causation. "Governance mechanisms may fulfil several functions at the same time. Consider open source licenses, for example. A well-known interpretation is that this mechanism (at least the copyleft one) solves the 'provisioning' problem, by keeping hackers motivated to contribute. A similar, but more sophisticated interpretation is, that copyleft attracts both 'rentseekers' and 'donators' in the process, thus maximizing contributions. In addition, a broader governance effect has been observed: copyleft (and open source in general) provides opportunities for companies to become involved by selling services or closed software on top, thus furthering the cause of OSS as a whole. What are your thoughts about multiple causation for the governance mechanisms you identify as being important?",

At the end of the call for papers, participants were asked to consider which more general lessons can be drawn from the particular experience of OSS. "Finally, the question remains to be answered whether and to what extent these governance mechanisms may apply to other kinds of self-governing learning processes. The Wikipedia project, which produces encyclopedia entries, is an obvious case in point. Moreover, might it even be possible to draw more general lessons for the governance of activities that are not self-governing? That is, may these insights be applicable in companies and institutions beyond self-governing processes? Or, putting it the other way round, precisely how special is this case of open source selfgovernance, and if so, why?',

Several scholars were invited to write a contribution, blending both empirical and theoretical observations. Most of them readily agreed. Incoming manuscripts were mutually peer reviewed by the participants. In the end, after thorough criticism by all involved, five articles emerged fit for publication. In the order of appearance in this journal, these are the following.

In his contribution entitled 'Developer autonomy in the FreeBSD open source project' Niels Jorgensen (Roskilde, Denmark) develops a fresh view on the considerable delegation of authority as practised in the FreeBSD project. He discusses the intricate relationships between the decentralized structure and committers' work motivation, frequent building (i.e., compiling the whole system), and parallel debugging. In particular, combining a software engineering perspective and a knowledge creation perspective, the crucial role of frequent building is emphasized, as a means of controlling the quality of committers' contributions, and as a source of tacit knowledge about the distribution as a whole. 
In 'Motivating job design as a factor in open source governance' Guido Hertel (Wuerzburg, Germany) explores the motivational processes in OSS, and suggests moving research away from a person-oriented focus towards a work-oriented focus. Using the Job Characteristics Model as his theoretical framework, he argues that it allows to identify job characteristics that explain the high motivation of participants. This new perspective may generate suggestions for improving work in new OSS projects, and in other contexts than OSS, in particular in software producing firms.

The next contribution, entitled 'The governance of open source initiatives: what does it mean to be community managed?', is written by Siobhán O'Mahony (Davis, CA, USA). After discussing how the open source frame has been diffused and adapted towards other contexts since the turn of the century, she sets out to articulate the parameters of what OSS participants value as central to 'community management'. Five core features are identified and analyzed: independence, pluralism, representation, decentralized decision-making, and autonomous participation. The analysis, she argues, provides a starting point for a better understanding of the newly evolving models in other contexts as inspired by OSS.

In her article 'The governance of free/open source software projects: monolithic, multidimensional, or configurational?' Lynne Markus (Waltham, MA, USA) provides a review and synthesis of the growing literature about OSS. After analyzing how OSS governance is being defined, she investigates whether it is conceptualized as a monolithic or as a multidimensional phenomenon. Subsequently, the goals that the literature associates with OSS governance are explored: solving collective action dilemma's, coordinating development work, and creating a positive climate for contributors. Finally, she proposes to focus upon the identification of configurations of OSS, and suggests six central dimensions of them. Future research, she concludes, should build upon prior research and adopt a 'comparative mindset'.

In the final contribution, 'Governance of open source software: state of the art', I weave the several strands in the arguments of the preceding authors together, and provide an overview of the governance mechanisms developed within OSS circles. I distinguish three types-and historical phases-of governance: 'spontaneous' governance, internal governance, and governance towards outside parties. Following up Markus' call, I employ an ideal type method and venture some conjectures about the typical configurations of OSS governance, at least for larger hacker communities. At the end, I discuss how the lessons of OSS are 'exported' by being applied to other types of products and incorporated within existing institutional contexts. 